\title{
Contraceptive Coil
}

National Cancer Institute

\section{Source}

National Cancer Institute. Contraceptive Coil. NCI Thesaurus. Code C92758.

A medical device that is inserted into the uterus to prevent pregnancy. 